\title{
SOME PRELIMINARY RESULTS ON THE DISTRIBUTION OF AFTERSHOCK SEQUENCES IN JAPAN-KURIL ISLANDS AND KAMCHATKA
}

\author{
Olasoglou E.M. ${ }^{1}$, Tsapanos T.M. ${ }^{1}$, Papadimitriou E.E. ${ }^{1}$ and Drakatos G.N. ${ }^{2}$ \\ ${ }^{1}$ Aristotle University of Thessaloniki, Department of Geology, 54124, Thessaloniki, Hellas, \\ lia_olasoglou@hotmail.com,tsapanos@geo.auth.gr,ritsa@geo.auth.gr \\ ${ }^{2}$ National Observatory of Athens, Institute of Geodynamis, Thision, 11810, Athens, Hellas, \\ g.drakat@noa.gr
}

\begin{abstract}
A study on the aftershock sequences distributed along the subductions in Japan and Kuril islands, as well as in Kamchatka is undertaken. Aftershock sequences, having a main shock magnitude $M_{w} \geq 7.0$, during the time period 1973-2013 are taken into account. The data used (mainshocks, aftershocks and foreshocks if there are any) are restricted in shallow focal depths. A large earthquake in Japan Trench (11 March $2011 / M w=9.0)$ occurred and for this reason the investigated area is of particular interest. Our study is concentrated on the spatial distribution of some parameters [Mc, $a, b$ (Gutenberg-Richter distribution) and $p, c, k$ (Omori's law)] closely associated with the seismic sequences statistics.
\end{abstract}

Keywords: aftershock sequences, spatial distribution of aftershock parameters, Japan, Kuril Islands, Kamchatka.

\section{Пєрí $\lambda \psi \psi \eta$}

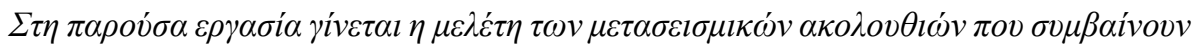

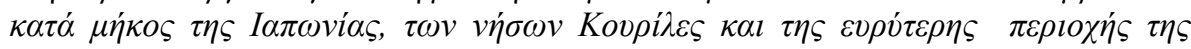

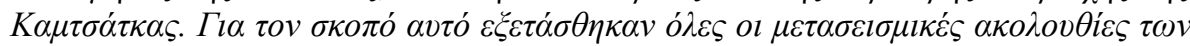

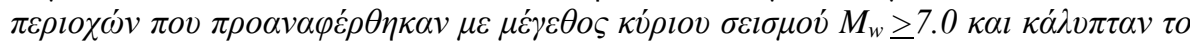

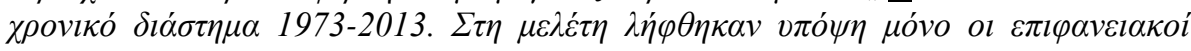

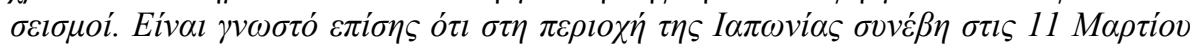

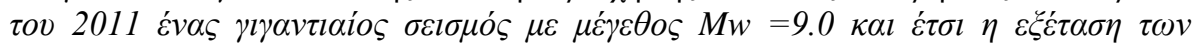

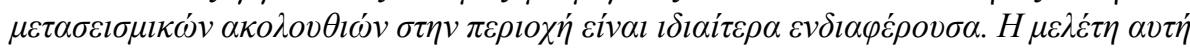

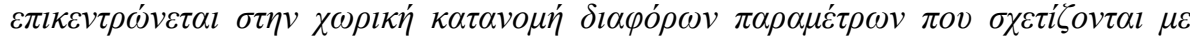

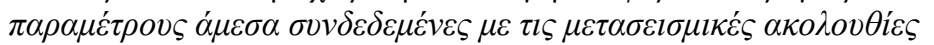

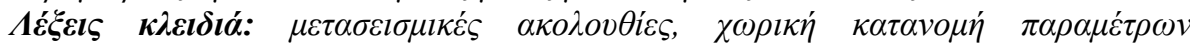

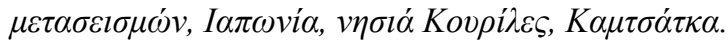

\section{Introduction}

A large amount of the residual seismic energy, caused by the heterogeneity of the focal region, is released with the aftershocks. Spatial and temporal variation of aftershocks parameters are sources of information about earthquake nucleation and reveal the internal crustal dynamics which related with the redistribution of the stress field in the fault zone (Dieterich, 1986; Frohlich, 1987; Tsapanos et al., 
1994; Heuret et al., 2011). Aftershocks of large earthquakes contribute to a significant hazard, which of course, can cause further damages to the already vulnerable constructions.

A large number of studies which focus on the properties of aftershock sequences have been published during the last decades (Tsapanos, 1990, 1992; Drakatos, 2000; Henry and Das, 2001; Felzer et al., 2004; Shcherbakov et al., 2005; Schorlemmer et al., 2005; Lay et al., 2009; Marsan and Lengliné, 2010; Goda, 2012; Scholz and Campos, 2012; Shcherbakov et al., 2013; MousaviBafrouei et al., 2014; among others). Moment release rates during mainshocks compared with moment release rates during aftershock sequences showed that the moment release rates of aftershock sequence are 30 times smaller than the maximum moment rate of the main shock (Kagan and Houston, 2005)

It is well known that aftershock sequences follow statistical laws. The most well known of these is the one referred to by seismologists as "Bath's law". According to this law, the difference D1 between the magnitude of the main shock $M$ and the largest aftershock M1 of an earthquake sequence has a statistical mean value of 1.2 (Richter, 1958) and is apparently independent of the magnitude of the earthquakes (Papazachos, 1974; Purcaru, 1974). One of the purposes of the present work is to examine this difference in the aftershock sequences occurred in the studied areas.

Characteristics of seismic sequences that may provide useful information are: the distribution in space and time, the total number of aftershocks, the completeness magnitude Mc, and the parameters $\mathrm{a}$ and $\mathrm{b}$ of Gutenberg-Richter relationship as well as the parameters of Omori's law. The last can be measured by the difference, D1.

This study confines itself to the computation of some simple but very useful aftershock parameters in the areas of Japan, Kuril Islands and Kamchatka, all parts of north-western Pacific Rim.

\section{Data processing}

All earthquakes, main shocks, fore- and aftershocks for the present study are extracted from the NEIC catalogue. The time span is 41 years, starting from January 1973 to December 2013. Earlier sequences (since 1960) are omitted given that they have not enough data (Shcherbakov et al., 2013). The earthquake magnitudes of the catalogue used are not provided in a unique scale. Local magnitudes, body wave magnitudes, among others are listed. For this reason and because there is a need for a unique magnitude scale, we converted all magnitudes in moment magnitude scale $\mathrm{M}_{\mathrm{w}}$, using for this purpose the empirical equations (Scordilis, 2006) by considering data from the whole earth. So, our sample is constituted of 31 seismic sequences with magnitude of the main shock $\mathrm{M}_{\mathrm{w}}$ 27.0. An earthquake is considered to be an aftershock if it occurs within one year after the main shock (Shcherbakov et al., 2013) and its location is within a distance L (in $\mathrm{Km}$ ) from the epicentre of the main shock. The evaluation of the distance $\mathrm{L}$ is based on the empirical relations Wells and Coppersmith (1994) between the magnitude and the rupture area. Useful relations for aftershock zones of large shallow earthquakes suggested by Henry and Das (2001), which concerning their fault dimension and aftershock area expansion. All the data used are of shallow depths $\mathrm{h} \leq 60 \mathrm{Km}$ (according to NEIC depth distribution). The magnitudes of the subsequent shocks are greater than or equal to 4.0 after 1973. In Figure (1) the main shocks under investigation, as well as their focal mechanisms are illustrated. The available data are 16 events for Japan, 5 earthquakes for the broader area of Kamchatka and 10 shocks for the Kuril Islands. As we observed the majority of the focal mechanisms are thrust faults given that they belong to subduction regions, while normal faults are also detected and a good paradigm is the giant event of $\mathrm{M}_{\mathrm{w}}=9.0$ which occurred in Japan Trench (Sato et al., 2012). As they pointed out Coulomb stress changes for normal fault aftershocks near Japan Trench which are found to be strongly related with the slip on the shallow portion of the faults. In the investigated area the focal mechanisms showed 1 megathrust, 3 of normal type, 6 reverse 3 strike slip 16 thrust and 1 underthrust. 


\section{The completeness magnitude Mc of the aftershock sequences in the studied areas}

The estimation of completeness magnitude is an essential and required step for any seismicity study. This magnitude, $\mathbf{M}_{\mathrm{C}}$, is assigned as the lowest magnitude which included all the events which generated in a space-time volume. This is crucial for further seismicity analysis, given that a magnitude lower than $M_{C}$ leads to bias results. Wiemer and Wyss (2000) assessed the minimum magnitude for complete earthquake data. Later, Woessner and Wiemer (2005) evaluated the quality of earthquake catalogues by an estimation of $\mathbf{M}_{\mathrm{C}}$ and its uncertainty. Mignan and Woessner (2012) provided an online resource for statistical analysis of seismicity focused on estimation of the completeness magnitude. The possible incompleteness of the data especially in the first time after the main shock plays a key role to the aftershock sequence processing (Lolli and Gasperini, 2006).

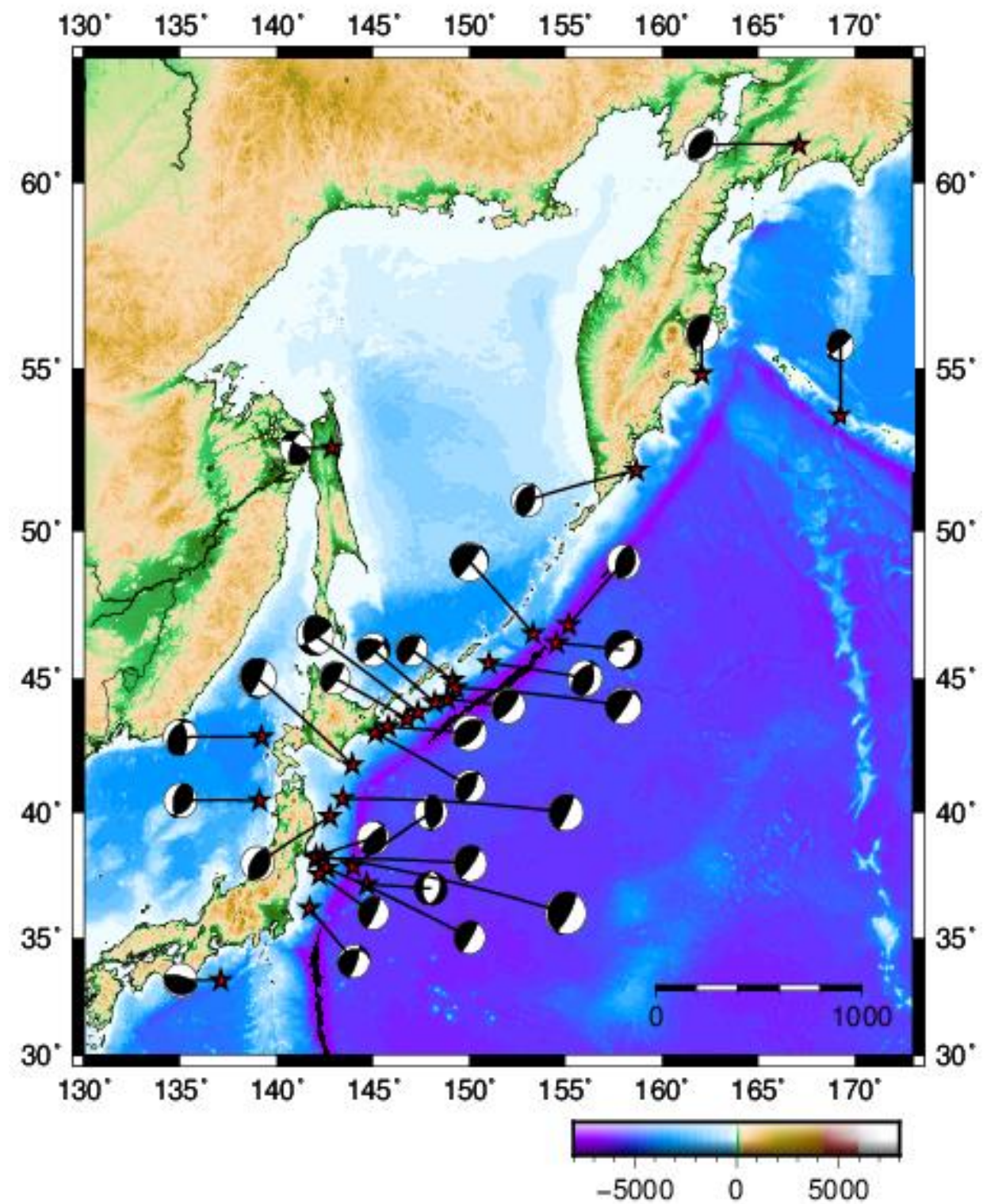

Figure 1 - The spatial distribution of the main shocks with their focal mechanism in the investigated area. 
We applied Z-map programme provided by Wiemer (2001) in order to assess the magnitude of completeness $\mathrm{Mc}$ for the 31 aftershock sequences in the area under investigation. Then the parameters $\mathrm{a}$ and $\mathrm{b}$ are computed using for this purpose the simple least square process A sample of the results is depicted in Figure (2). It is obvious (Fig. 3) that almost the dominant completeness magnitude of the examined is $M_{C}=4.9$. The completeness magnitude ranged from 4.1 to 5.5. The results for $\mathrm{Mc}$, $\mathrm{a}$ and $\mathrm{b}$ values are portrayed in Table 1. An interesting observation is coming out from the spatial distribution of the b parameter. It is clearly shown that in Hokkaido and Honshu, islands of Japan, the b-values are slightly lower than those calculated for Kuril Islands and Kamchatka. These differences need further investigation and according to our knowledge this may depends on the tectonics of the areas. Two b-values one at Honshu Island (during 2012) and one at Kuril Islands (during 1978) have values greater than 2.0 which are 2.35 and 2.05, respectively. For the areas of Japan and Kuril islands (Shcherbakov et al., 2013) found that b-values ranged between 0.9 and 1.6 with a mean at 1.21. For a-values areas with lower b-value tend to have lower a-values while those with larger b-values have greater a-values although admittedly a short number of exception to this generalization are also observed to exist.

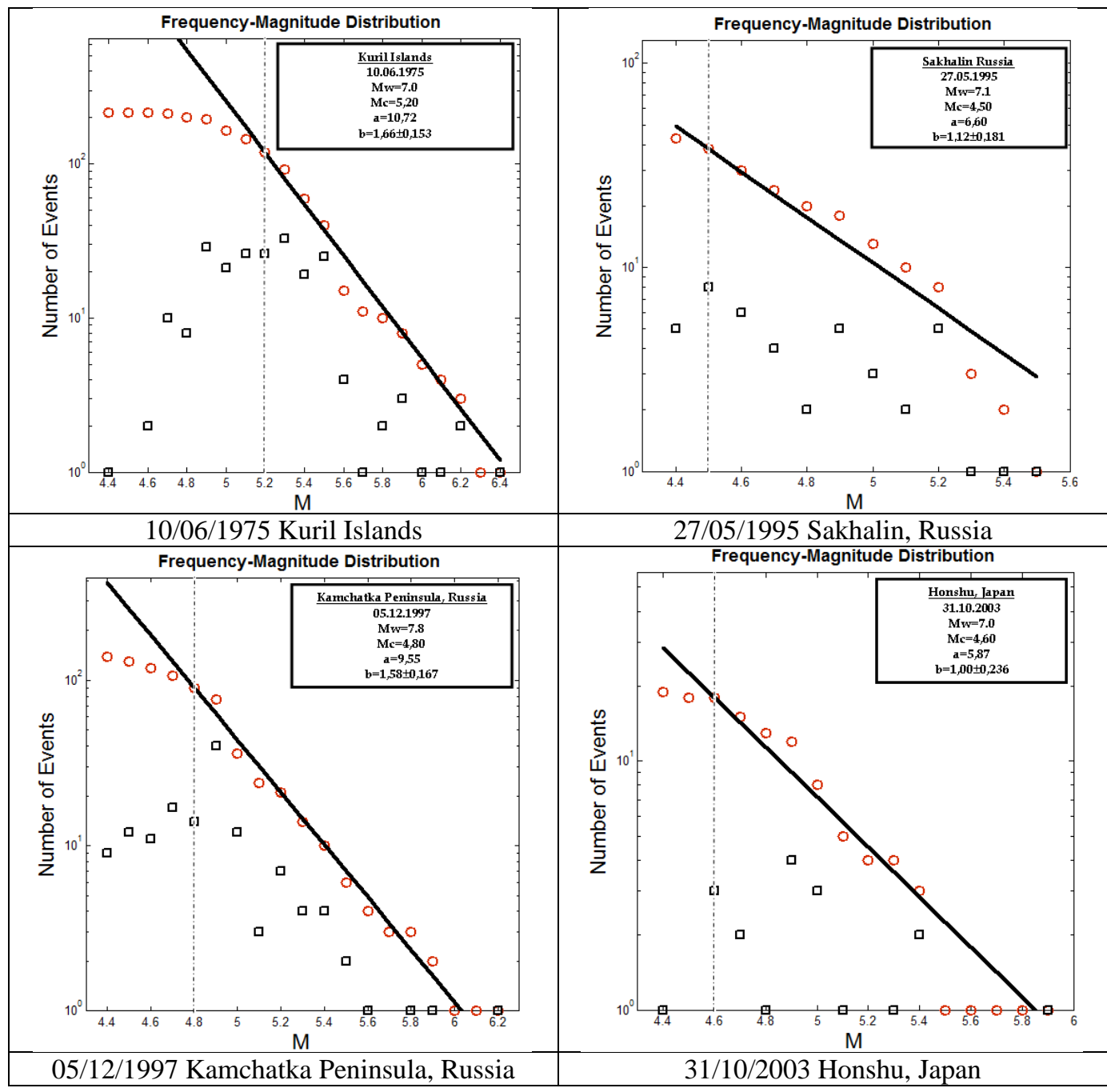




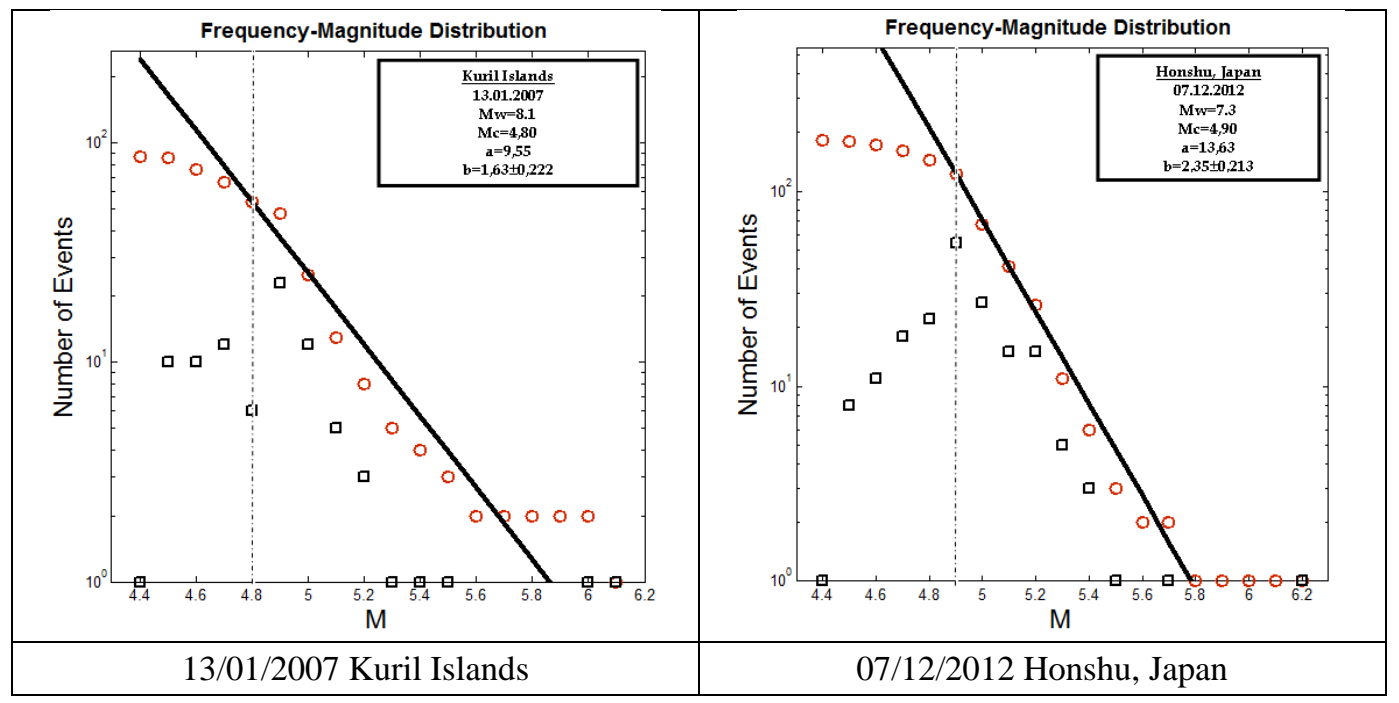

Figure 2 - A sample of completeness magnitude graphs of the studied aftershock sequences.

\section{Mc-Frequency}

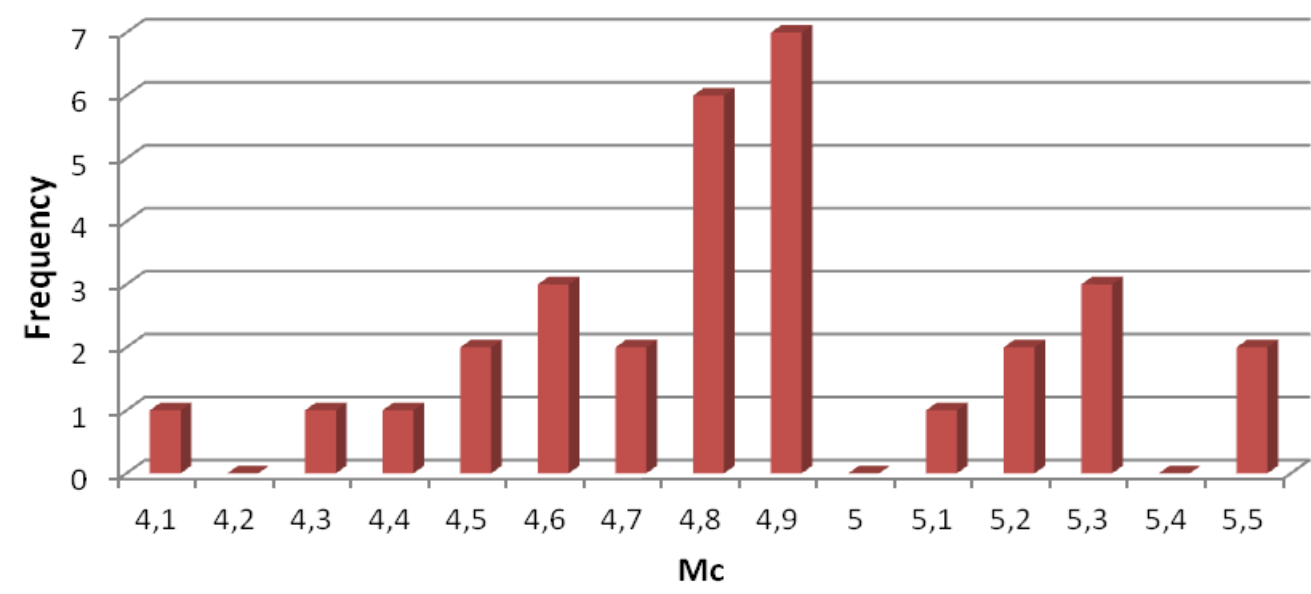

Figure 3 - The range of completeness magnitudes where the magnitude $M_{C}=4.9$ is dominated.

\section{The difference D1 between the main shock and its largest aftershock}

The difference between the main shock and the largest aftershock in an aftershock sequences is called by "Bath's law" and its statistical mean is proposed as 1.2 It is interesting that the statistical distribution of D1 for earthquake sequences located at the examine areas is actually characterized by not one but rather two well defined peaks. One of them has a mean of 1.0 and is in good agreement with Bath's law. Papazachos (1974) found also the same values for the aftershocks sequences occurred in Greece. The second peak corresponds to the values of 1.8. Tsapanos (1990) found also a same pattern for the aftershock sequences distributed in the circum Pacific Rim. The second mean of the three values found by the same author is exactly the same as the second peak observed for the whole investigated area. He also made an effort to associate these values with the stress field in the focal area. Although the data are not enough (especially for the second peak) this may could be a tendency when we add the results from all the aftershock sequences, with an alternative for the second peak is to be disappeared with plenty of data. In Figure (4) the histogram of the difference 
D1 for the aftershock sequences of the whole examined area are illustrated. Shcherbakov et al. (2015) computed D1-values for Japan and Kuril Islands and found o mean of D1=1.11. This value is compatible with our results (first peak).

D1

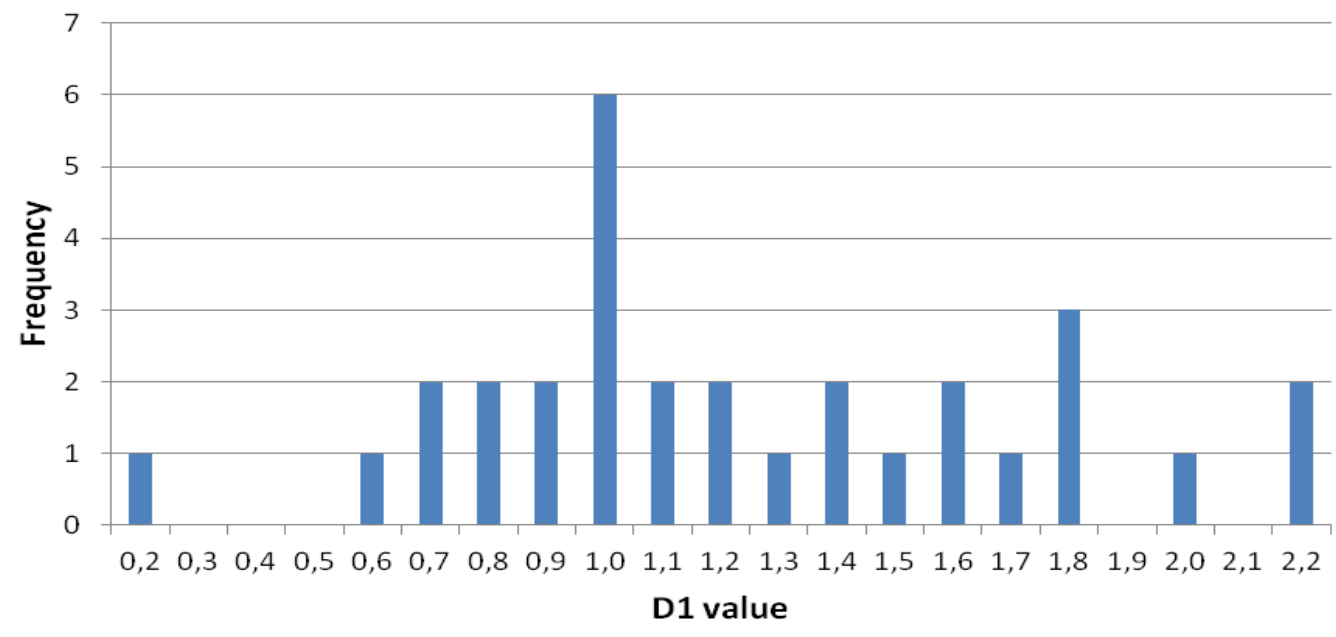

Figure 4 - The values of the difference D1 between the magnitudes of the main shock and its largest aftershock in the seismic zones of the examined area.

Other authors related this difference with various parameters. For example, Gibowitz (1973) has shown that this difference is associated with the stress drop in the main shock. He points out that the difference M - M1 is small when the stress drop in the main shock is low, or the remaining stress is high, and vice versa. Also Okada (1979) has shown that this difference may be related to the parameter $b$ of the Gutenberg-Richter equation, while Purcaru (1974) observed that the difference D1 is a linear function of b. Additionally, Mogi (1963) and Scholz (1968) have shown from laboratory experiments on rocks that the parameter $b$ depends on the stress conditions and on the homogeneity of the materials in the focal area.

\section{Omori's law in the studied area}

According to the work of Omori (1895) the aftershock rate is roughly proportional to the inverse of the time, $t$, elapsed after the main shock and is given by the following equation:

\section{Equation 1 - The origin formula of the Omori's law:}

$$
n(t)=k /(t+c)
$$

In eq. (1) $c$ and $k$ are coefficients, while time $t$ is the time since the main shock origin and $n(t)$ is the aftershock frequency measured over a certain time interval.

A modified version, where aftershocks decay as a power law is introduced by Utsu (1961);

Equation 2 - The modified version of Omori's law:

$n(t)=\frac{k}{(t+c)^{p}}$

Coefficients $\mathrm{t}, \mathrm{k}$ and $\mathrm{c}$ (in eq 1 and 2) are of same meaning as in the origin formula. The p-value is the decay parameter, which, according to Utsu (1961), varies between 0.7 and 1.5. 
Table 1 - Overall values of the computed aftershock parameters of the two empirical laws

(Gutenberg-Richter and Omori) in the studied area. The date, the magnitude of the main shock and the place of the generation of aftershock activity are also listed.

\begin{tabular}{|c|c|c|c|c|c|c|c|c|c|}
\hline \multirow{2}{*}{ No } & \multirow{2}{*}{ DATE } & \multirow{2}{*}{ Mw } & \multirow{2}{*}{ Region } & \multicolumn{3}{|c|}{ Gutenberg-Richter } & \multicolumn{3}{|c|}{ Omori } \\
\hline & & & & Mc & $\mathbf{a}$ & $\mathbf{b}$ & $\mathbf{p}$ & c & $\mathbf{k}$ \\
\hline 1 & $1973 / 06 / 17$ & 7.7 & Hokkaido, Japan & 5.50 & 9.99 & 1.51 & 0.94 & 0.08 & 10.00 \\
\hline 2 & $1976 / 01 / 21$ & 7.0 & Kuril Islands & 5.30 & 10.66 & 1.69 & 1.60 & 0.76 & 10.00 \\
\hline 3 & $1978 / 03 / 24$ & 7.6 & Kuril Islands & 5.30 & 12.67 & 2.05 & 1.15 & 0.62 & 95.80 \\
\hline 4 & $1978 / 06 / 12$ & 7.7 & Honshu, Japan & 4.80 & 5.90 & 0.88 & 0.73 & 0.01 & 16.90 \\
\hline 5 & $1980 / 02 / 23$ & 7.0 & Kuril Islands & 5.50 & 7.43 & 1.19 & 0.71 & 0.40 & 10.00 \\
\hline 6 & $1982 / 07 / 23$ & 7.1 & Honshu, Japan & 4.90 & 7.41 & 1.20 & 0.69 & 0.01 & 10.00 \\
\hline 7 & $1983 / 05 / 26$ & 7.4 & Honshu, Japan & 4.80 & 6.18 & 0.94 & 1.08 & 0.20 & 19.70 \\
\hline 8 & $1984 / 03 / 24$ & 7.2 & Kuril Islands & 4.90 & 7.85 & 1.34 & 0.75 & 1.16 & 10.00 \\
\hline 9 & 1989/11/01 & 7.4 & Honshu, Japan & 4.90 & 7.51 & 1.18 & 0.75 & 0.01 & 10.00 \\
\hline 10 & $1990 / 11 / 06$ & 7.1 & $\begin{array}{l}\text { Komandorskiye Ostrova, } \\
\text { Russia }\end{array}$ & 4.40 & 4.66 & 0.81 & 1.32 & 2.93 & 10.00 \\
\hline 11 & $1991 / 12 / 22$ & 7.6 & Kuril Islands & 5.10 & 11.80 & 1.96 & 0.58 & 0.01 & 14.80 \\
\hline 12 & $1993 / 07 / 12$ & 7.7 & Hokkaido, Japan & 4.80 & 7.61 & 1.18 & 1.30 & 0.35 & 10.00 \\
\hline 13 & $1993 / 11 / 13$ & 7.0 & $\begin{array}{l}\text { Kamchatka Peninsula, } \\
\text { Russia }\end{array}$ & 4.60 & 4.22 & 0.66 & 1.16 & 5.00 & 10.00 \\
\hline 14 & $1994 / 10 / 04$ & 8.3 & Kuril Islands & 5.20 & 10.27 & 1.52 & 0.81 & 0.71 & 76.40 \\
\hline 15 & $1994 / 12 / 28$ & 7.8 & Honshu, Japan & 5.20 & 7.65 & 1.14 & 0.78 & 0.07 & 10.00 \\
\hline 16 & $1995 / 05 / 27$ & 7.1 & Sakhalin, Russia & 4.50 & 6.60 & 1.12 & 1.03 & 0.10 & 10.00 \\
\hline 17 & $1995 / 12 / 03$ & 7.9 & Kuril Islands & 4.90 & 8.05 & 1.16 & 0.75 & 5.00 & 10.00 \\
\hline 18 & $1997 / 12 / 05$ & 7.8 & $\begin{array}{l}\text { Kamchatka Peninsula, } \\
\text { Russia }\end{array}$ & 4.80 & 9.55 & 1.58 & 1.10 & 0.85 & 25.60 \\
\hline 19 & $2003 / 09 / 25$ & 8.3 & Hokkaido, Japan & 4.80 & 7.08 & 1.02 & 0.76 & 0.01 & 14.70 \\
\hline 20 & $2003 / 10 / 31$ & 7.0 & Honshu, Japan & 4.60 & 5.87 & 1.00 & 1.00 & 0.16 & 24.40 \\
\hline 21 & $2004 / 09 / 05$ & 7.4 & Honshu, Japan & 4.50 & 6.03 & 0.96 & 1.24 & 0.34 & 146.50 \\
\hline 22 & $2004 / 11 / 28$ & 7.0 & Hokkaido, Japan & 4.30 & 4.95 & 0.79 & 1.13 & 4.77 & 10.00 \\
\hline 23 & $2005 / 08 / 16$ & 7.2 & Honshu, Japan & 4.10 & 4.14 & 0.59 & 0.72 & 0.01 & 10.00 \\
\hline 24 & $2006 / 04 / 20$ & 7.6 & $\begin{array}{l}\text { Kamchatka Peninsula, } \\
\text { Russia }\end{array}$ & 4.80 & 9.27 & 1.49 & 1.08 & 0.05 & 44.70 \\
\hline 25 & $2006 / 11 / 15$ & 8.3 & Kuril Islands & 4.90 & 12.18 & 1.98 & 0.89 & 0.26 & 222.30 \\
\hline 26 & $2007 / 01 / 13$ & 8.1 & Kuril Islands & 4.80 & 9.55 & 1.63 & 1.17 & 0.23 & 107.60 \\
\hline 27 & $2008 / 07 / 19$ & 7.0 & Honshu, Japan & 4.60 & 7.79 & 1.42 & 1.15 & 1.46 & 10.00 \\
\hline 28 & $2009 / 01 / 15$ & 7.4 & Kuril Islands & 4.70 & 8.85 & 1.59 & 0.60 & 0.01 & 10.00 \\
\hline 29 & $201103 / 11$ & 9.1 & Honshu, Japan & 5.30 & 8.73 & 1.14 & 0.65 & 0.20 & 10.00 \\
\hline 30 & $2012 / 12 / 07$ & 7.3 & Honshu, Japan & 4.90 & 13.63 & 2.35 & 0.48 & 0.01 & 20.50 \\
\hline 31 & $2013 / 10 / 25$ & 7.1 & Honshu, Japan & 4.70 & 6.87 & 1.15 & 1.37 & 0.23 & 10.00 \\
\hline
\end{tabular}


Kisslinger and Jones (1991) suggested that $\mathrm{k}$ is depended on the total number of aftershocks in the sequence and c on the activity in the earliest part of the sequence. Shcherbakov et al. (2006) taken into account three laws (Gutenberg and Richter, Omori's and Bath's) proposed that c-parameter plays the role of a characteristic time for establishment of Gutenberg and Richter scaling. This time increases systematically with a decreasing lower magnitude cutoff. The k-parameter slightly varies with lower magnitude cutoff of the sequence the parameter $p$ depends on the physical properties of the material in the focal region and its common mean is 1.0. Tsapanos (1995) suggested the p-values, estimated from 170 aftershock sequences in the Pacific rim, follows the normal distribution with a mean $\mathrm{p}=0.935$ and this values is in good agreement with the value proposed by Davis and Frohlich (1991) of $\mathrm{p}=0.892$ (swarms excluded). Davis and Frohlich (1991) also found for all aftershock sequences in all tectonic structures of the Earth a mean $\mathrm{p}=0.868$ and they suggested that aftershock statistics do vary depending on regional tectonics. Tsapanos (1995) also computed for the whole west Pacific a value of $p=0.912$ which is compatible with the one found for the whole Pacific. The computed values of $\mathrm{p}, \mathrm{c}$ and $\mathrm{k}$ in the present study are listed in Table 1 . The parameter $p$ varies from 0.48 to 1.60 with a mean $p=0.95$, which is almost the same with one $\mathrm{p}=0.98$ found by Shcherbakov et al. (2013) for Japan and Kuril islands. It is also compatible with the previously referred (from other authors) values and it is in good agreement with the common mean $\mathrm{p}=1.0$. The parameter $\mathrm{c}$ varies from 0.01 to 5.00 with a mean 0.84 , while k-parameter has values from 10 to 222 with a mean 33. The mean c-value for Kamchatka aftershock sequences is $\mathrm{c}=1,97$ which is larger than the one calculated for e.g. Kuril islands with a corresponding c-value $=0.92$. This means that the aftershock sequences occurred in Kamchatka seem to be very active during the first times after the main shock occurrence. One may argue to the results that in Kamchatka only three earthquakes occurred. But this is well observed in Kuril island and Honshu where the number of aftershock sequences is approximately of same number. Kuril islands show exactly the same behaviour. Following Kisslinger and Jones (1991) the mean c-value $=1.30$ for e.g. Hokkaido, while its mean kvalue $=11,18$, we can suggested that the activity is high in the first part of the aftershock sequences in this region but the aftershock sequences released with short number of aftershocks.

\section{Conclusions}

This paper presents some preliminary considerations of aftershock sequences occurred in the northwestern part of the Pacific Rim. Japan, Kuril Islands, as well as Kamchatka are the areas under investigation. The data collection and their further processing play a key role. They must be accurate, homogeneous and complete. So the data sets were extracted from NEIC catalogue, their magnitudes were expressed in Mw and their completeness (Mc) is assessed for each one of the sequences. It was observed that the most common Mc is the magnitude 4.9. Software Z-map applied for this purpose and the parameter $a$ and $b$ of the Gutenberg-Richter distribution calculated by the least square fitting. Generally speaking we observed that the b values evaluated in Kuril Islands and Kamchatka are larger than those found for Hokkaido and Honshu.

We also defined the Bath's law parameter (D1) for which we observed two peaks with values of 1.0 and 1.8, respectively, although one can argue for the limited data used for the second peak. The majority of the examined aftershock sequences belong to subduction zones, where large amount of energy accumulated along the plate interface. In such cases the main shock releases a part of the stored energy while the remaining energy, which is still large, is released as large aftershock. In such cases small values of D1 parameter are expected.

The Z-map package is also applied for obtaining the parameters derived by the Omori's law, which are the known p, c and k components for each individual of the studied aftershock sequences. The results indicated that high $\mathrm{p}$-value means that the number of aftershocks decay faster in time than for a lower p-value. The other two parameters of Omori law c and k provided important insight into aftershocks behaviour. According to Kisslinger (1996) the k-value depends on the total number of events in the sequence and reflects the earliest part of the sequence and accounts for the observed fact that the earliest aftershocks do not follow a steady decay rate rather their rate increases in the first minutes to hours, then begins to decrease. On the other hand c-parameter depends on the activity in the earliest part of 
the sequence. The tectonic setting and the mode of faulting are factors other than fault surface properties that might control the behaviour of the sequences. The temporal properties of California's aftershock sequences studied by Narteau et al. (2008) and they found that the c-parameter is a decreasing function of the magnitude of aftershocks and that it varies across different types of faulting. They also suggested that the time delay before the onset of the power law aftershock decay rate is in average shorter for earthquakes that generated in thrust than in normal faults. For earthquakes which occurred in strike-slip faults this time delay is of intermediate values. All our results are listed in a very informative table where one can read the values computed (Mc, a, b, p, c and k) through this study. Due to intense aftershock activity in short time-span after the mainshock occurrence the c-value of Omori's law (Utsu et al., 1995; Kisslinger, 1996; Woessner et al., 2004) is commonly considered as a time offset estimating for incomplete detection of aftershock activity.

Average values of p-parameter are: 1.03 for Hokkaido, 0.89 for Honshu, 0.90 for Kuril Islands and 1.14 for Kamchatka. Corresponding estimates of $\mathrm{c}$ and $\mathrm{k}$ components are: 1.30 and 11.2 for Hokkaido, 0.23 and 24.8 for Honshu, 0.92 and 56.7 for Kuril Islands and 1.79 and 20.1 for Kamchatka. Based on the obtained results we can conclude that in average the activity, in Kamchatka, in the first times after the mainshock occurrence the activity is higher than the other examined regions. The larger average k-parameter, as shown, is evaluated for Kuril Islands (56.7) lead us to the conclusion that the aftershock activity in sequences released with large number of aftershocks, while Kamchatka comes second.

The obtained results of the paper (albeit they are preliminary ones) are in quite good agreement with previous ones estimated by numerous authors. Their spatial distribution reveals the distribution of the homogeneity of the crustal material, as well as the distribution of the stresses which prevail.

\section{References}

Davis, S.D. and Frohlich, C., 1991. Single-link cluster analysis of earthquake aftershocks: Decay laws and regional variations, J. Geophys. Res., 96, 6335-6350.

Dieterich, J., 1986. A model for the nucleation of earthquake slip. In: Earthquake Source Mechanism, Das, S., Boatwright, J. and Scholz, C., eds., Geophysical Monograph Series, Am. Geoohys. Un., 37, 37-47, Washington, D.C., U.S.A.

Drakatos, G., 2000. Relative Seismic Quiescence before Large Aftershocks, Pure and Appl. Geophysics, 157, 1407-1421.

Felzer, K.R., Abercrombie, R.E. and Ekstrom, G., 2004. A common origin of aftershocks, foreshocks, and multiplets, Bull. Seismol. Soc. Am., 94, 88-98.

Frohlich, C., 1987. Aftershocks and temporal clustering of deep earthquakes, J. Geophys. Res., 92, 1394-13956.

Gibowitz, S.J., 1973. Stress drop and aftershocks, Bull. Seism. Soc. Am., 63, 1433-1446.

Goda, K., 2012. Nonlinear response potential of mainshock-aftershock sequences from Japanese earthquakes, Bull. Seismol. Soc. Am., 102, 2139-2156.

Henry, C. and Das, S., 2001. Aftershock zones of large shallow earthquakes: Fault dimensions, aftershock area expansion, and scaling relations, Geophys. J. Int., 147, 272-293.

Heuret, A., Lallemand, S., Funiciello, F., Piromallo, C. and Faccenna, C., 2011. Physical characteristics of subduction interface type seismogenic zones revisited, Geochem. Geophys. Geosyst., 12, no. Q01004, doi: 10.1029/2010GC003230.

Lay, T., Kanamori, H., Ammon, C.J., Hutko, A.R., Furlong, K. and Rivera, L., 2009. The 2006-2007 Kuril Islands great earthquake sequence, J. Geophys. Res., 114, B113208, doi: 10.1029/2008JB006280.

Lolli, B. and Gasperini, P., 2006. Comparing different models of aftershock rate decay: The role of the catalog, Tectonophysics, 423, 43-59.

Kagan, Y.Y. and Houston, H., 2006. Relation between mainshock rupture process and Omori's law for aftershock moment release rate, Geophys. J. Int., 163, 1039-1048.

Kisslinger, C., 1996. Aftershock and Fault Zone Properties, Advances in Geophysics, 38, 1-36.

Kisslinger, C.L. and Jones, L., 1991. Properties of aftershock sequences in southern California, $J$. Geophys. Res., 96, 11, 947-958. 
Marsan, D. and Lengliné, O., 2010. A new estimation of the decay of aftershock density with distance to the mainshock, J. Geophys. Res., 115, B09302.

Mignan, A. and Woessner, J., 2012. Estimating the magnitude of completeness for earthquake catalogs, Community Online Resource for Statistical Seismicity Analysis, doi: 10.5078/corssa-00180805.

Mogi, K., 1963. Some discussions on aftershocks, foreshocks and earthquake swarms the fracture of a semi-infinite body caused by an inner stress origin and its relation to the earthquake phenomena, Bull. Earthq. Res. Inst., 41, 615-658.

Mousavi-Bafrouei, S.H., Mirzaei, N. and Shabani, E., 2014. A declustered earthquake catalog for the Iranian Plateau, Annals of Geophyisics, 57(6), So653, doi: 10.4401/ag-6395.

Narteau, C., Shebalin, P. and Hollschneider, M., 2008. The onset of the aftershock decay rate across different stress regimes, Geophys. Res. Abstrs., 10, EGU2008-A-05624.

Okada, M., 1979. Statistical distribution of the difference in magnitude between the main shock and its largest aftershock, J. Seism. Soc. Japan, 32, 462-476.

Omori, F., 1895. On the aftershocks of earthquakes, J. Coll. Sci. Imp. Univ., Tokyo, 7, 111-200.

Papazachos, B.C., 1974. On certain aftershock and foreshock parameters in the area of Greece, Ann. Geofisica, 27, 497-515.

Purcaru, G., 1974. On the statistical interpretation of the Bath's law and some relations in aftershock statistics, Geol. Inst. Technic. And Ec. Study Geophys. Prosp., Bucharest, 10, 35-84.

Richter, C.F., 1958. Elementary Seismology, W.H. Freeman, San Francisco, 768 pp.

Sato, T., Hirotsuka, S. and Mori, J., 2012. Coulomb stress change for the normal fault aftershocks triggered near the Japan Trench by the $2011 \mathrm{M}_{\mathrm{w}} 9.0$ Tohoku-Oki earthquake, Earth Planets space, 64, 1239-1243.

Scordilis, E.M., 2006. Empirical global relatins converting Ms and mb to moment magnitude, $J$. Seismol., 10, 225-236, doi: 10.107/s10950-006-9012-4.

Scholz, C.H., 1968. The frequency-magnitude relation of microfracturing in rock and its relation to earthquake, Bull. Seism. Soc. Am., 58, 399-415.

Scholz, C.H. and Campos, J., 2012. The seismic coupling of subduction zones revisited, J. Geophys. Res., 117, no. B05310, doi: 10.1029/ 2011JB009003.

Schorlemmer, D., Wiemer, S. and Wyss, M., 2005. Variations in earthquake size distribution across different stress regimes, Nature, 437, 539-542.

Shcherbakov, R., Turcotte, D.L. and Rundle, J.B., 2005. Aftershock statistics, Pure Appl. Geophys., 162, 1051-1076.

Shcherbakov, R., Turcotte, D.L. and Rundle, J.B., 2006. Scaling properties of the Parkfield aftershock sequences, Null. Seismol. Soc. Am., 96, S376-S384.

Shcherbakov, R., Goda, K., Ivanian, A. and Atknson, G.M., 2013. Aftershock statistics of major subduction earthquakes, Bull. Seismol. Soc. Am, 103(6), doi: 10.185/0120120337.

Tsapanos, T.M., 1990. Spatial distribution of the difference between the magnitudes of the main shock and the largest aftershock in the circum Pacific belt, Bull. Seismol. Soc. A., 80(5), 1180-1189.

Tsapanos, T.M., 1995. The temporal distribution of aftershock sequences in the subduction zones of the Pacific, Geophys. J. Int., 123, 633-636.

Tsapanos, T., Papazachos, C., Moutafi, Z., Gabrielides, J. and Spyrou, T., 1994. Properties of the globally distributed aftershock sequences: Emphasis in the circum-Pacific belt, Proceedings of the $7^{\text {th }}$ Congress, Bull. Geol. Soc. Greece, l(XXX/5), 151-158, Thessaloniki, May 1994.

Utsu, T., 1961. A statistical study on the occurrence of aftershocks, Geophys. Mag. Tokyo, 30, 521-603.

Utsu, T., Ogata, Y. and Matsu'ura, R.S., 1995. The centenary of the Omori formula for a decay law of aftershock activity, Journal of Physics of the Earth, 43, 1-33.

Wiemer, S. and Wyss, M., 2000. Minimum magnitude of completeness in earthquake catalogs: Examples from Alaska, the Western United States, and Japan, Bull. Seismol. Soc. Am., 90, 859-869.

Wiemer, S., 2001. A software package to analyze seismicity:ZMAP, Seismological Research Letters, 72, 337-382.

Wells, D. and Coppersmith, K., 1994. New Empirical relationships among magnitude, rupture length, rupture width, rupture area, and surface displacement, Bull. Seismol. Soc. Am., 84, 974-1002.

Woessner, J., Hauksson, E., Wiemer, S. and Neukomm, S., 2004. The 1997 Kagoshima (Japan) earthquake doublet: A quantitative analysis of aftershock aate changes, Geophysical Research Letters, 31, Article ID: L03605.

Woessner, J. and Wiemer, S., 2005. Assessing the quality of earthquake catalogues: Estimating the magnitude of completeness and its uncertainty, Bull. Seismol. Soc. Am., 95(2), 684-698. 